\title{
Relationship between Changes in Functional Capacity and Anthropometric, Clinical and Psychological Indicators in Cardiac Patients Participating in Cardiac Rehabilitation Program
}

\author{
Hadavi Mohammad Mahdi', Sadeghi Masoumeh', Kheiry Mohammad Ali², \\ Hamidreza Roohafza1 ${ }^{1}$, Rafati Fard Mohammad1,3* \\ ${ }^{1}$ Cardiac Rehabilitation Research Center, Cardiovascular Research Institute, Isfahan University of Medical Sciences, Isfahan, Iran \\ ${ }^{2}$ Iranian Hospital, Dubai, UAE \\ ${ }^{3}$ Health Science/Exercise Physiology, Clinical Research Development Unit, Hajar Hospital, Shahrekord University of Medical \\ Sciences, Shahrekord, Iran \\ Email: *Rafati2821@yahoo.com
}

How to cite this paper: Mahdi, H.M., Masoumeh, S., Ali, K.M., Roohafza, H. and Mohammad, R.F. (2021) Relationship between Changes in Functional Capacity and Anthropometric, Clinical and Psychological Indicators in Cardiac Patients Participating in Cardiac Rehabilitation Program. Health, 13, 1303-1313.

https://doi.org/10.4236/health.2021.1311095

Received: June 20, 2021

Accepted: November 15, 2021

Published: November 18, 2021

Copyright $\odot 2021$ by author(s) and Scientific Research Publishing Inc. This work is licensed under the Creative Commons Attribution International License (CC BY 4.0).

http://creativecommons.org/licenses/by/4.0/

\begin{abstract}
Background: Cardiac rehabilitation (CR) is a multifaceted treatment that can increase the survival and quality of life of cardiac patients by increasing their functional capacity (FC). In this study, we aimed to investigate the FC changes of cardiac patients after the CR program in different subgroups in terms of anthropometric, clinical, and psychological indices. Materials and Methods: This is a descriptive retrospective study that has been derived from the results of a Cohort study at the Rehabilitation Research Center of the Cardiovascular Research Institute of Isfahan (Iran), from 2006 to 2017. In this study, the dependent variable is functional capacity changes based on Mets obtained in exercise testing at the beginning and end of the CR program. Independent variables included age, sex, dyslipidemia, diabetes, smoking, and Body mass index, type of intervention, depression, and EF. Results: The sample size is 1250 cardiovascular patients, of which 917 (73.5\%) are male and 331 (26.5\%) are female. Functional capacity after the CR program significantly increased in all age, gender, body mass index, hypertension, hyperlipidemia, diabetes, smoking, depression, EF, and type of operation performed (angioplasty or open-heart surgery) subgroups, $(\mathrm{p}<0.001)$. Using multiple linear regression analysis, a significant relationship was found between Mets changes and only the variables of gender, depression, and EF. Conclusion: The results of this
\end{abstract}


study show the importance of rehabilitation programs in the secondary prevention of cardiovascular disease in different subgroups and factors such as gender, level of primary depression, and EF less than 35 are the most important factors affecting functional capacity increase after CR program in heart patients.

\section{Keywords}

Functional Capacity, Heart Patients, Cardiac Rehabilitation

\section{Introduction}

Heart disease is one of the leading causes of disability and the most common cause of death worldwide [1]. The prevalence of cardiovascular risk factors in the population of Iran is the same as some Middle Eastern countries and more than Western countries [2]. The main risk factors for cardiovascular disease are age, sex, total cholesterol, low-density lipoprotein (LDL) cholesterol, systolic blood pressure, diabetes, and smoking, most of which can be corrected [3]. Inactivity is one of the main risk factors for heart disease and improving physical activity in coronary heart disease reduces the mortality of these patients, which is directly related to the dose of physical activity in patients [4]. Regular exercise in elderly patients with heart failure can also improve aerobic capacity and improve heart function [5]. Cardiac Rehabilitation is one of the treatment and prevention methods recommended by the American Heart Association and the European Heart Association for all patients with coronary heart disease or heart failure [6] [7] [8].

Cardiac rehabilitation is a multifaceted treatment that includes exercise and other interventions to reduce the risk factors for heart disease [9]. Cardiac rehabilitation reduces the mortality of coronary heart disease patients and reduces the number of hospitalizations [10] [11]. In patients with heart failure, although the effect of cardiac rehabilitation in reducing mortality has not been significant, but it can improve the quality of life of these patients [12].

One of the important factors in the effectiveness of cardiac rehabilitation programs is the positive effect of these programs on patients' functional capacity. Because improving functional capacity increases patients' life expectancy and reduces their mortality [9]. Various studies have been performed in this field and most of them show the improvement of functional capacity in cardiac patients admitted to the cardiac rehabilitation units. But so far the rate of improvement of functional capacity in the different subgroups have not been studied separately [13] [14]. In this study, in addition to examining the changes in FC in the whole target population, the differences of these changes in different subgroups in terms of anthropometric, clinical and psychologic indices have been investigated. 


\section{Methods and Analysis}

\subsection{Study Design}

This study is derived from the results of a cohort study at the Cardiac Rehabilitation Research Center of the Isfahan Heart Research Institute from 2006 to 2017 The sample size of the study is 1250 people whose information was extracted from the database entered in the Heart Research Institute. Inclusion criteria: All patients referred to the cardiac rehabilitation unit during the years 2006 to 2017 who have completed at least one 12-session rehabilitation course including aerobic and resistance exercise with cardiac monitoring, nutrition and psychological counseling, control and treatment of cardiac risk factors and self-care training programs. Other criteria for inclusion in the study include lack of Uncompensated heart failure, providing consent to participate in the study, lack of contraindication for CR, consent of the physician for his/her patient participation in the study, and undergoing percutaneous coronary intervention (PCI) or cardiac surgery at most 2 months previously. Exclusion criteria: includes all patients who did not complete the rehabilitation period due to reasons such as major depression, orthopedic problems and other physical disorders, uncontrolled hypertension and arrhythmia. All patients had been received the necessary training and care under the same conditions, including:

1) Three one-hour sessions of physical activity per week (warm up phase for 5 to 10 minutes, aerobic exercise using a treadmill, cycle ergometer and arm ergometer for 30 to 40 minutes and finally cool down phase for 5 to 10 minutes with reduced activity intensity) with heart monitoring under the supervision of a rehabilitation team consisting of a cardiologist, a sports medicine specialist and a nurse.

2) Participating in a 30- to 45-minute training session to control risk factors, including hyperlipidemia, diabetes, smoking, as well as psychosocial training under the supervision of a psychiatrist once during the course.

3) Participating in a 30- to 45-minute nutrition counseling session at the beginning of the cardiac rehabilitation course.

The recorded information of all patients before and after the rehabilitation period was evaluated. This information includes:

1) Demographic information, anthropometric indices and risk factors by a researcher-made questionnaire.

2) Patients' heart function is based on the amount of cardiac ejection fraction (EF) recorded in the echocardiographic report obtained at the beginning and end of the course by the same cardiologist using a standard device.

3) Functional capacity (FC) of patients based on the amount of Mets recorded in the patient's exercise test report performed by a standard exercise testing device with Modified Bruce protocol obtained at the beginning and end of the course.

4) Patients' depressive status based on Beck Depression Inventory (BDI): This questionnaire. Includes 21 four-choice questions, each of which scored $0-3$. 
This questionnaire has been studied for validity and reliability in some studies in Iran and its cut-off points are as follows: Patients with a BDI score of 0 - 9 are normal, those attaining a score of 10 - 19 have mild depression, those with a score of 20 - 29 have moderate depression and those with a score of over 29 have severe depression.

5) All patients who completed the cardiac rehabilitation program were followed up in two stages: after 3 months and one year of cardiac rehabilitation.

\subsection{Statistical Analysis}

Kolmogorov-Smirnov test was used to investigate the normal distribution of variables and descriptive statistics in form of tables were used to analyze the data. Comparisons between groups were performed using Independent samples t-test and analysis of variance (ANOVA) was used to compare the mean differences between groups and Multiple linear regression analysis was used to investigate the effects of different indices on the rate of MET changes. All statistical analyses were performed using the SPSS version 21 (SPSS Inc., Chicago, IL, USA). The significance level ( $\mathrm{p}$ value) was considered $<0.05$.

\section{Results}

In this study, 1250 cardiovascular patients were studied. The results show that $73.5 \%$ of our statistical population are men and $26.5 \%$ are women, $40.9 \%$ of these people are under 55 years old and $59.1 \%$ are over 55 years old. Other patients' characteristics are shown in Table 1.

Table 2 shows the findings related to Mets changes in terms of anthropometric, psychological and clinical indicators. By performing paired t-test and examining the changes in each group separately, it was observed that the increase in Mets (which indicates the patient's functional improvement) after cardiac rehabilitation was statistically significant in all groups.

Table 3 shows the mean changes of METS in terms of age groups, sex, body mass index, hypertension, hyperlipidemia, diabetes, smoking, depression, EF, and type of intervention, using analysis of variance.

In Table 4, multiple linear regression analysis was used to investigate the effects of anthropometric, clinical and psychological indices on the mean changes of Mets. Findings show that after adjusting the effect of confounding variables, a statistically significant relationship was found between Mets changes and variables of gender, depression and EF, but no statistically significant relationship was found in other variables.

\section{Discussion}

Functional capacity is a very important factor in diagnosing the recovery of cardiovascular patients and also predicts mortality in heart patients [15]. In this study, the mean functional capacity in terms of METs, after the end of the rehabilitation period, was significantly increased in all participating patients. This 
Table 1. Sociodemographic and clinical characteristics of study population $(\mathrm{N}=1248)$.

\begin{tabular}{|c|c|}
\hline Variable & Number (\%) \\
\hline \multicolumn{2}{|l|}{ Age } \\
\hline$>55$ & $511(40.9)$ \\
\hline$\leq 55$ & $738(59.1)$ \\
\hline \multicolumn{2}{|l|}{ Gender } \\
\hline Men & $917(73.5)$ \\
\hline Women & $331(26.5)$ \\
\hline \multicolumn{2}{|l|}{ Marital status } \\
\hline Single & $24(1.9)$ \\
\hline Married & $1224(98.1)$ \\
\hline \multicolumn{2}{|l|}{ Schooling } \\
\hline Graduate & $173(13.9)$ \\
\hline Undergraduate & $1075(86.1)$ \\
\hline \multicolumn{2}{|l|}{ Body Mass Index } \\
\hline$<25$ & $360(29.0)$ \\
\hline $25-35$ & $842(67.8)$ \\
\hline$>35$ & $40(3.2)$ \\
\hline \multicolumn{2}{|l|}{ Hypertension } \\
\hline Yes & $766(61.4)$ \\
\hline No & $482(38.6)$ \\
\hline \multicolumn{2}{|l|}{ Diabetes } \\
\hline Yes & $862(69.1)$ \\
\hline No & $386(30.9)$ \\
\hline \multicolumn{2}{|l|}{ Hyperlipidemia } \\
\hline Yes & $576(46.2)$ \\
\hline No & $671(53.8)$ \\
\hline \multicolumn{2}{|l|}{ Smoking } \\
\hline Yes & $197(15.8)$ \\
\hline No & $1053(84.2)$ \\
\hline \multicolumn{2}{|l|}{ depression } \\
\hline Yes & $459(36.7)$ \\
\hline No & $791(63.3)$ \\
\hline \multicolumn{2}{|l|}{ Ejection fraction } \\
\hline$>35$ & $155(12.4)$ \\
\hline$\leq 35$ & $1085(87.6)$ \\
\hline \multicolumn{2}{|l|}{ Type of intervention } \\
\hline Non-surgical & $537(42.9)$ \\
\hline Surgical & $713(57.1)$ \\
\hline
\end{tabular}


Table 2. Comparison of mean Mets changes before and after intervention between different variables.

\begin{tabular}{|c|c|c|c|}
\hline \multirow{3}{*}{ Variable } & \multicolumn{3}{|c|}{ Mean Mets changes } \\
\hline & Start $\mathrm{CR}^{\mathrm{a}}$ & Finish $\mathrm{CR}^{\mathrm{a}}$ & \multirow{2}{*}{ p-value ${ }^{*}$} \\
\hline & $\mathrm{M} \pm \mathrm{SD}^{\mathrm{b}}$ & $\mathrm{M} \pm \mathrm{SD}$ & \\
\hline \multicolumn{4}{|l|}{ Age } \\
\hline$>55$ & $9.51 \pm 2.93$ & $12.46 \pm 3.35$ & 0.001 \\
\hline$\leq 55$ & $7.75 \pm 2.90$ & $10.43 \pm 3.28$ & 0.001 \\
\hline \multicolumn{4}{|l|}{ Gender } \\
\hline Men & $9.07 \pm 2.89$ & $12.08 \pm 3.20$ & 0.001 \\
\hline Women & $6.35 \pm 2.43$ & $8.44 \pm 2.53$ & 0.001 \\
\hline \multicolumn{4}{|l|}{ Body Mass Index } \\
\hline$<25$ & $8.64 \pm 3.04$ & $11.43 \pm 3.21$ & 0.01 \\
\hline $25-30$ & $8.58 \pm 2.97$ & $11.36 \pm 3.42$ & 0.01 \\
\hline $31-35$ & $7.65 \pm 2.88$ & $10.39 \pm 3.55$ & 0.01 \\
\hline$>35$ & $6.04 \pm 2.83$ & $8.48 \pm 3.41$ & 0.01 \\
\hline \multicolumn{4}{|l|}{ Hypertension } \\
\hline Yes & $7.85 \pm 2.85$ & $10.61 \pm 3.40$ & 0.001 \\
\hline No & $8.67 \pm 3.10$ & $11.44 \pm 3.43$ & 0.001 \\
\hline \multicolumn{4}{|l|}{ Diabetes } \\
\hline Yes & $7.69 \pm 2.93$ & $10.14 \pm 3.16$ & 0.001 \\
\hline No & $8.64 \pm 3.02$ & $11.56 \pm 3.47$ & 0.001 \\
\hline \multicolumn{4}{|l|}{ Hyperlipidemia } \\
\hline Yes & $8.22 \pm 3.04$ & $10.91 \pm 3.50$ & 0.001 \\
\hline No & $8.44 \pm 2.99$ & $11.29 \pm 3.64$ & 0.001 \\
\hline \multicolumn{4}{|l|}{ Smoking } \\
\hline Yes & $8.45 \pm 3.17$ & $11.10 \pm 3.26$ & 0.001 \\
\hline No & $8.31 \pm 3.01$ & $11.09 \pm 3.46$ & 0.001 \\
\hline \multicolumn{4}{|l|}{ depression } \\
\hline Yes & $8.66 \pm 3.01$ & $11.27 \pm 3.40$ & 0.001 \\
\hline No & $7.46 \pm 2.92$ & $10.59 \pm 3.52$ & 0.001 \\
\hline \multicolumn{4}{|l|}{ Ejection fraction } \\
\hline$>35$ & $7.66 \pm 3.08$ & $11.12 \pm 3.08$ & 0.001 \\
\hline$\leq 35$ & $8.41 \pm 3.01$ & $11.08 \pm 3.48$ & 0.001 \\
\hline \multicolumn{4}{|c|}{ Type of intervention } \\
\hline Non-surgical & $8.54 \pm 3.18$ & $11.5 \pm 3.71$ & 0.001 \\
\hline Surgical & $8.08 \pm 2.82$ & $10.7 \pm 3.06$ & 0.001 \\
\hline
\end{tabular}

${ }^{\mathrm{a}} \mathrm{CR}$ (Cardiac rehabilitation), ${ }^{\mathrm{b}} \mathrm{M} \pm \mathrm{SD}$ (Mean \pm Standard deviation). 
Table 3. Comparison of mean differences of Mets between different groups using analysis of variance.

\begin{tabular}{|c|c|c|}
\hline Variable & Mean changes of Mets \pm SD & $\mathrm{p}$ \\
\hline \multicolumn{3}{|l|}{ Age } \\
\hline$>55$ & $2.71 \pm(2.52)$ & \multirow{2}{*}{0.2} \\
\hline$\leq 55$ & $2.51 \pm(2.40)$ & \\
\hline \multicolumn{3}{|l|}{ Gender } \\
\hline Men & $2.79 \pm(2.61)$ & \multirow{2}{*}{0.001} \\
\hline Women & $2.05 \pm(1.83)$ & \\
\hline \multicolumn{3}{|l|}{ Body Mass Index } \\
\hline$<25$ & $2.98 \pm(2.52)$ & \multirow{3}{*}{0.001} \\
\hline $25-35$ & $2.63 \pm(2.47)$ & \\
\hline$>35$ & $2.30 \pm(2.33)$ & \\
\hline \multicolumn{3}{|l|}{ Hypertension } \\
\hline Yes & $2.76 \pm(2.7)$ & \multirow{2}{*}{0.1} \\
\hline No & $2.77 \pm(2.66)$ & \\
\hline \multicolumn{3}{|l|}{ Hyperlipidemia } \\
\hline Yes & $2.69 \pm(2.71)$ & \multirow{2}{*}{0.4} \\
\hline No & $2.85 \pm(2.64)$ & \\
\hline \multicolumn{3}{|l|}{ Smoking } \\
\hline No & $2.71 \pm(2.65)$ & \multirow{2}{*}{0.1} \\
\hline yes & $2.66 \pm(2.38)$ & \\
\hline \multicolumn{3}{|l|}{ depression } \\
\hline Minimal & $2.44 \pm(2.45)$ & \multirow{2}{*}{0.011} \\
\hline Mild-moderate-severe & $2.92 \pm(2.76)$ & \\
\hline \multicolumn{3}{|l|}{ Ejection fraction } \\
\hline$>35$ & $3.18 \pm(2.18)$ & \multirow{2}{*}{0.02} \\
\hline$\leq 35$ & $2.52 \pm(2.48)$ & \\
\hline \multicolumn{3}{|l|}{ Type of intervention } \\
\hline Non-surgical & $2.84 \pm(2.79)$ & \multirow{2}{*}{0.1} \\
\hline Surgical & $2.54 \pm(2.37)$ & \\
\hline
\end{tabular}

Table 4. Relationship between age, sex, body mass index, hypertension, diabetes, hyperlipidemia, smoking, depression, EF, Surgical and Mets changes using regression analysis.

\begin{tabular}{ccc}
\hline Variable & Beta $(95 \% \mathrm{CI})$ & p-value \\
\hline Age & $-0.003(4.32)$ & 0.9 \\
\hline
\end{tabular}




\section{Continued}

\begin{tabular}{ccc}
\hline Sex & $-0.154(0.48)$ & 0.001 \\
Body Mass Index & $0.023(-0.43)$ & 0.5 \\
Hypertension & $0.016(-0.27)$ & 0.7 \\
Diabetes & $-0.004(-0.82)$ & 0.16 \\
Hyperlipidemia & $0.011(0.12)$ & 0.9 \\
Smoking & $0.016(0.91)$ & 0.2 \\
Depression & $0.077(0.48)$ & 0.04 \\
Ejection fraction & $-0.079(-1.24)$ & 0.03 \\
Intervention & $-0.046(-0.43)$ & 0.2 \\
\hline
\end{tabular}

finding is consistent with most studies in this field, including the study of McKee et al. (2020), Esteki et al. (2018) and Shabani et al. (2011) [13] [16] [17]. But it contradicts the study of Ayoubi et al. (2005), which did not find a significant change in patients' functional capacity.

In order to determine the most effective and predictive indicators in functional capacity change among anthropometric, clinical and psychological indices, multiple regression analysis was performed, in which three variables of gender, depression and $\mathrm{EF}<35$ were identified. In this study, age was not an effective indicator and predictor of changes in functional capacity. By comparing the difference between the average changes in functional capacity in the age group under 55 years and above 55 years, no statistically significant difference was found.

Having compared the difference between the mean change of METS in terms of body mass indexes of the subjects, it was observed that the improvement of functional capacity in patients with body mass index $\leq 25$ was more than patients with body mass index between $35-35$ and above $35 \mathrm{~kg} / \mathrm{cm}^{2}$, but this difference was not statistically significant. [18] reported an inverse relationship between body mass index and functional capacity. Excess body fat reduces skeletal muscle oxygen uptake and impairs functional capacity [19]. In addition, in people with high body mass index, type II muscle fibers increase while type 1 decrease. It can lead to a significant reduction in oxygen uptake which is accompanied by a decrease in functional capacity [20].

Gender variable was an effective and predictive indicator of change in functional capacity. The results of this study showed that in men the change in Mets was significantly higher than women. This finding is consistent with a study by McKee et al., Who found that Mets had more changes in men than women [16] but it is inconsistent with the study of Kakoli et al., Who stated that gender is not an influential factor in increasing functional capacity [21].

This study also showed that the rate of METS increase was significantly higher in people with depression at the beginning of the CR period compared to nondepressed patients, which could be due to the fact that these patients had low functional capacity because of depression at the beginning of the CR period and 
gradually, with the betterment of depression, they found a significant increase in METS compared to the other group. In the study of McKee et al., no significant relationship was found between depression and functional capacity [16].

Other influential and predictive factors in changes in functional capacity are clinical indices. In this study, by comparing the mean change of METS between patients with hypertension and without hypertension, patients with diabetes and without diabetes, patients with hyperlipidemia and without hyperlipidemia and patients in the surgical and non-surgical groups, no statistically significant difference was found. But this difference was statistically significant in patients with EF less than or equal to 35 compared to patients with EF greater than 35. Also, multiple linear regression analysis showed that among the clinical variables, only the EF is an effective indicator in improving functional capacity. This finding was consistent with the study of Bjarnason-Wehrens B et al. (2019) [22] but in contrast to the studies of MALOBERTI et al. (2019) and PERETTI, A et al. (2020) which showed that there was no significant relationship between functional capacity improvement and EF [23] [24]. This inconsistency can be attributed to the amount of initial functional capacity of patients with severe heart failure and it can be said that patients with low EF are more affected by the rehabilitation programs.

\section{Conclusion}

In general, the results of this study showed that the cardiac rehabilitation program is important in the secondary prevention of CVD and cardiac rehabilitation can increase the functional capacity of heart patients in all age groups and different subgroups by activating physiological mechanisms such as oxygen uptake from the blood, increasing the oxidative response and increasing cardiac output [25] [26]. Among anthropometric, clinical and psychologic indices, gender variable, level of primary depression and EF less than 35 were identified as the most effective indicators affecting the improvement of functional capacity. Taken together, these findings may reinforce the importance of rehabilitation programs for patient's recovery and survival.

\section{Acknowledgements}

We would like to thank deputy of research of Isfahan University of Medical Sciences-Cardiovascular Research Institute for financial support.

\section{Conflicts of Interest}

The authors declare no conflicts of interest regarding the publication of this paper.

\section{References}

[1] Mendis, S., et al. (2011) Global Atlas on Cardiovascular Disease Prevention and Control. World Health Organization, Geneva. 
[2] Ebrahimi, M., et al. (2011) Coronary Artery Disease and Its Risk Factors Status in Iran: A Review. Iranian Red Crescent Medical Journal, 13, 610. https://doi.org/10.5812/kowsar.20741804.2286

[3] D’Agostino Sr, R.B., et al. (2008) General Cardiovascular Risk Profile for Use in Primary Care: The Framingham Heart Study. Circulation, 117, 743-753. https://doi.org/10.1161/CIRCULATIONAHA.107.699579

[4] Freeman, A.M., Taub, P.R., Lo, H.C. and Ornish, D. (2019) Intensive Cardiac Rehabilitation: An Underutilized Resource. Current Cardiology Reports, 21, Article No. 19. https://doi.org/10.1007/s11886-019-1104-1

[5] Slimani, M., et al. (2018) The Effects of Physical Training on Quality of Life, Aerobic Capacity, and Cardiac Function in Older Patients with Heart Failure: A Meta-Analysis. Frontiers in Physiology, 9, 1564. https://doi.org/10.3389/fphys.2018.01564

[6] Thomas, R.J., et al. (2019) Home-Based Cardiac Rehabilitation: A Scientific Statement from the American Association of Cardiovascular and Pulmonary Rehabilitation, the American Heart Association, and the American College of Cardiology. Journal of the American College of Cardiology, 74, 133-153.

https://doi.org/10.1097/HCR.0000000000000447

[7] Oldridge, N. and Taylor, R.S. (2020) Cost-Effectiveness of Exercise Therapy in Patients with Coronary Heart Disease, Chronic Heart Failure and Associated Risk Factors: A Systematic Review of Economic Evaluations of Randomized Clinical Trials. European Journal of Preventive Cardiology, 27, 1045-1055. https://doi.org/10.1177/2047487319881839

[8] Piepoli, M.F., et al. (2016) European Guidelines on Cardiovascular Disease Prevention in Clinical Practice: The Sixth Joint Task Force of the European Society of Cardiology and Other Societies on Cardiovascular Disease Prevention in Clinical Practice (Constituted by Representatives of 10 Societies and by Invited Experts) Developed with the Special Contribution of the European Association for Cardiovascular Prevention \& Rehabilitation (EACPR). European Heart Journal, 37, 2315-2381. https://doi.org/10.1093/eurheartj/ehw106

[9] Kachur, S., et al. (2017) Impact of Cardiac Rehabilitation and Exercise Training Programs in Coronary Heart Disease. Progress in Cardiovascular Diseases, 60, 103 114. https://doi.org/10.1016/j.pcad.2017.07.002

[10] Bachmann, J.M., et al. (2018) Association of Cardiac Rehabilitation with Decreased Hospitalizations and Mortality after Ventricular Assist Device Implantation. JACC: Heart Failure, 6, 130-139. https://doi.org/10.1016/j.jchf.2017.11.002

[11] Anderson, L., et al. (2016) Exercise-Based Cardiac Rehabilitation for Coronary Heart Disease: Cochrane Systematic Review and Meta-Analysis. Journal of the American College of Cardiology, 67, 1-12. https://doi.org/10.1016/j.jacc.2015.10.044

[12] Taylor, R.S., et al. (2018) Impact of Exercise-Based Cardiac Rehabilitation in Patients with Heart Failure (ExTraMATCH II) on Mortality and Hospitalisation: An Individual Patient Data Meta-Analysis of Randomised Trials. European Journal of Heart Failure, 20, 1735-1743. https://doi.org/10.1002/ejhf.1311

[13] Shabani, R., et al. (2011) Effects of Cardiac Rehabilitation Program on Physical Capacity, Blood Pressure, Heart Rate Recovery and Myocardial Oxygen Consumption in Patients Undergoing Coronary Artery Bypass Grafting. Medical Science Journal of Islamic Azad University- Tehran Medical Branch, 21, 108-113.

[14] Sadeghi, M., et al. (2012) Is There Any Difference between Non-Obese Male and Female in Response to Cardiac Rehabilitation Programs? Journal of Research in 
Medical Sciences: The Official Journal of Isfahan University of Medical Sciences, 17, 787.

[15] Bonow, R.O., et al. (2011) Braunwald's Heart Disease e-Book: A Textbook of Cardiovascular Medicine. Elsevier Health Sciences, Amsterdam.

[16] McKee, A. (2020) Association of Various Physiological and Fitness Markers to Body Fat Percentage in Physically Inactive Adults. Northern Illinois University, DeKalb.

[17] Esteki, S., Gholami, M. and Jalalian, R. (2018) The Effect of Coenzyme Q10 and Exercise Training on Some Indicators of the Hemodynamicfor Patients with Heart Failure. Medical Journal of Mashhad University of Medical Sciences, 61, 950-957.

[18] Cc, L., Udaya, I. and Vinutha Shankar, S. (2014) Effect of Body Mass Index on Cardiorespiratory Fitness in Young Healthy Males. International Journal of Scientific and Research Publications, 25.

[19] S Chatterjee, J. (2005) A Critical Review of Irrigation Techniques in Acute Wounds. International Wound Journal, 2, 258-265.

https://doi.org/10.1111/j.1742-4801.2005.00123.x

[20] Fry, C.S., et al. (2014) Fibre Type-Specific Satellite Cell Response to Aerobic Training in Sedentary Adults. The Journal of Physiology, 592, 2625-2635. https://doi.org/10.1113/jphysiol.2014.271288

[21] Kakoli, M., Kargarfard, M. and Rabiei, K. (2009) Changes in Functional Capacity of Post Myocardial Infarction Patients in Three Cardiac Rehabilitation Program Length.

[22] Bjarnason-Wehrens, B. (2019) Recommendations for Resistance Exercise in Cardiac Rehabilitation: Do They Need Reconsideration? European Journal of Preventive Cardiology, 26, 1479-1482. https://doi.org/10.1177/2047487319856124

[23] Maloberti, A., et al. (2019) Vascular Aging and Disease of the Large Vessels: Role of Inflammation. High Blood Pressure \& Cardiovascular Prevention, 26, 175-182. https://doi.org/10.1007/s40292-019-00318-4

[24] Vallerio, P., et al. (2020) Thoracic Radiotherapy as a Risk Factor for Heart Ischemia in Subjects Treated with Chest Irradiation and Chemotherapy and without Classic Cardiovascular RISK Factors. Radiotherapy and Oncology, 152, 146-150.

https://doi.org/10.1016/j.radonc.2020.07.004

[25] Sadeghi, M., Izadi, A., Hadavi, M.M., Fard, M.R. and Roohafza, H. (2020) Comparison of the Effect of 12- and 24-Session Cardiac Rehabilitation on Physical, Psychosocial and Biomedical Factors in Ischemic Heart Disease Patients. Hormone Molecular Biology and Clinical Investigation, 41, Article ID: 20190023. https://doi.org/10.1515/hmbci-2019-0023

[26] Hanson, P. and Nagle, F. (1987) Isometric Exercise: Cardiovascular Responses in Normal and Cardiac Populations. Cardiology Clinics, 5, 157-170.

https://doi.org/10.1016/S0733-8651(18)30543-5 